\title{
Modification and Simulation of Noncircular Gear Reversing Mechanism of Pumping Unit
}

\author{
Rui Zhang, Linfang Lu, Fang Li and Tingting Wang* \\ School of Mechanical Engineering, Zhengzhou University, Zhengzhou 450001, China \\ ${ }^{*}$ Corresponding author
}

\begin{abstract}
There is a very broad application prospects in incomplete noncircular gear reversing mechanism in the pumping unit, because of its advantage of automatic reversing and intermittent variable speed movement. Incomplete noncircular gears are usually based on empirical formula design, without considering the special mechanism of the reversing mechanism, resulting in large volume, difficult processing and large margin. In this paper, the dynamic simulation of the pumping mechanism is carried out by ADAMS and the strength analysis of incomplete noncircular gears is carried out by ANSYS. Then, the parameters of the noncircular gear are optimized based on the theoretical bending fatigue strength formula, which reduces the size and quality of the reversing mechanism greatly. The optimized result satisfies the working conditions of the reversing mechanism, there is important guiding significance in the practical application.
\end{abstract}

Keywords-noncircular gear; reversing mechanism; dynamic simulation; optimization design; strength

\section{INTRODUCTION}

Pumping unit is divided into beam pumping unit and non-beam pumping unit in generally. About the beam-pumping unit, there is a serious rigidity impact when the beam-pumping unit is reversed, and its long stroke is more difficult to work, the capacity of balance is poor, the energy consumption is large, and the efficiency is low. Non-beam pumping unit structure is more complex, processing is more difficult, the higher the cost ${ }^{[1]}$. In the pumping system, the reversing mechanism converts the rotational motion of the motor into the reciprocating pumping movement of the sucker rod, which is an important research direction of the pumping unit. The pumping unit of the noncircular gear could achieve intermittent motion of mechanical structure according to the advantages of intermittent motion, there is a higher accuracy, in addition, the special nature of noncircular gear can control the time of the working stroke and the idle stroke, and this improves mechanical efficiency and reduces losses ${ }^{[2]}$. However, in the case of actual operation, noncircular gear motion mechanism prone to movement interference ${ }^{[3]}$, that is, the first teeth and the last teeth of the driving gear are punctured. At present, most of the research on noncircular gears is CAD / CAE simulation design ${ }^{[4,5]}$, and the method of the mending tooth shape of noncircular gears is not studied.

In this paper, the research object is the pumping unit that is the noncircular gear reversing mechanism, which is developed by the designers independently. In view of the traditional design, which mainly relies on the empirical formula to design the key components, and lacks consideration of the actual working conditions and other issues, so we combined with advanced CAD/CAE and other computer aided design technology to explore the optimization design program of incomplete noncircular gear which based on actual operation of the pumping unit to achieve the reduction of noncircular gear volume and quality in the requirements of the premise, and facilitate the manufacturing process, these have theoretical guidance significance and practical application value to engineering practice.

\section{INCOMPLETE NONCIRCULAR GEAR TRADITIONAL DESIGN}

A. Working Principle of Reversing Mechanism and Analysis of Working Conditions

The new type reversing mechanism of pumping unit of Incomplete noncircular gear works as shown in Figure 1, the body consists of three incomplete noncircular gears and three cylindrical gears, the incomplete noncircular gear I is coaxial with the cylindrical gear I, the incomplete noncircular gear III is coaxial with the cylindrical gear II; Cylindrical gears I and cylindrical full gears II have equal number of teeth and modulus. Driver noncircular gear II for uniform motion and constant torque, driven incomplete noncircular gear III and incomplete noncircular gear I for variable speed reversing, cylindrical gear III for the output gear. And driven wheel for variable speed reversing movement, which drives the driven roller and sucker rod up and down reciprocating motion.

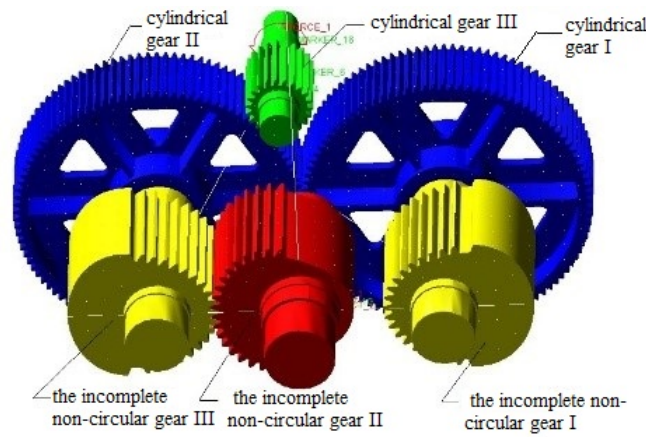

FIGURE I. WORKING PRINCIPLE OF INCOMPLETE NONCIRCULAR GEAR REVERSING MECHANISM

It is known that the load torque of an oil field pumping unit is $120 \mathrm{kN} \mathrm{m}$, plus $70 \%$ of the balance block, the drum's diameter is $596 \mathrm{~mm}$, the cylindrical gear II and the cylindrical gear III transmission ratio is 4.59, and the noncircular gear maximum transmission ratio is 1.5. So the reversing mechanism load torque is: 


$$
120 \times(1-70 \%) \times 0.5962=10.728 \mathrm{kN} \mathrm{m}
$$

The pumping stroke is $6 \mathrm{~m}$, and the number of stroke is 2 times / min, so the number of revolutions of a roller is:

$$
6 /(\pi \times 0.596)=3.204 r
$$

The speed is:

$$
3.20446 \times 2 \times 2=12.818 \mathrm{rpm}
$$

take the drum's speed for $13 \mathrm{rpm}$.

\section{B. Design of Incomplete Noncircular Gears}

1) Calculation of modulus of noncircular gear: The pressure angle is $20^{\circ}$, the height coefficient of the tooth top $h_{a}=1.0 \mathrm{~m}$, the height of the tooth root $h_{f}=1.25 \mathrm{~m}$ with no displacement and take the noncircular gear equivalent teeth $Z_{I I I}=31$ taking into account the standard tooth profile. Bending fatigue Strength formula:

$$
m=\sqrt[3]{\frac{2 k T_{1} Y_{F a} Y_{S a}}{\phi_{d} z_{I I I}^{2}\left[\sigma_{F}\right]}}
$$

Where $\mathrm{m}$ is the modulus of the noncircular gear; $\mathrm{k}$ is the load factor, k=1.5; $T_{1}$ is the load torque; $Y_{F a}$ is the tooth profile; $Y_{F a}=2.51 ; Y_{S a}$ is the stress correction coefficient, $Y_{S a}=1.63 ; \phi_{d}$ is the tooth width coefficient, since the two supports are arranged symmetrically with respect to the driver noncircular gear, and both gears are hard teeth, and $\phi_{d}=1.1$; The allowable stress of the gear:

$$
\left[\sigma_{F}\right]=\frac{K_{N} \sigma_{\lim }}{S}
$$

Where: $K_{N}$ is the life factor, and $K_{N}=0.978, \sigma_{\text {lim }}$ is the limit of gear bending fatigue, the gear's material is 20CrMnMo which is carburized and quenched. $\sigma_{\text {lim }}=860 \mathrm{MPa}$; $\mathrm{S}$ is the fatigue strength safety factor, according to the actual working conditions take $\mathrm{S}=1.6$, the calculation can be obtained: $\left[\sigma_{F}\right]=525.7 \mathrm{MPa}$, $m=10.282834$, for the center distance from the rounding, modulus correction $m=10.518061$.

2) Calculation of the tooth width: Deform the formula (1) and obtained tooth width coefficient:

$$
\phi_{d}=\frac{2 \boldsymbol{k} \boldsymbol{T}_{1} \boldsymbol{Y}_{F a} \boldsymbol{Y}_{S a}}{\boldsymbol{m}_{1}^{3} \boldsymbol{z}_{I I I}^{2}\left[\sigma_{F}\right]}=1.028
$$

$$
\phi_{d}=\frac{b}{d_{1}}
$$

Then $b=335.2 \mathrm{~mm}$, take the cylindrical gear tooth width of $340 \mathrm{~mm}$, the tooth width coefficient $\phi_{d}=1.043$.

3) Tooth bending stress checking:

$$
\begin{aligned}
& \sigma_{F 1}=\frac{2 \times 1.5 \times 1.0728 \times 10^{7} \times 4.59 \times 2.51 \times 1.63}{1.043 \times 10.518061^{3} \times 31^{2}} \\
& =518 \boldsymbol{M P a} \leq\left[\sigma_{F}\right]=525.7 \mathbf{M P a}
\end{aligned}
$$

so the calculation results are reasonable.

After determining equivalent modulus and tooth width of noncircular gear, because there is impact when the reversing mechanism into the engagement, the first wheel width of the drive wheel is increased according to experience.

\section{ANALYSIS ON OPERATION CONDITION OF NONCIRCULAR GEAR REVERSING MECHANISM}

\section{A. Analysis of Noncircular Gear Reversing Mechanism}

\section{1) Model establishment:}

After the modeling is done in SolidWorks, then the assembly file is imported into the ADAMS / View environment, and the noncircular gear reversal mechanism simulation model is obtained.

Add material properties, motion pairs and constraints to each part, but the noncircular gears can't be constrained by the gear pair, it needs to set the contact collision method to define its relative motion relationship and to set a reasonable contact collision parameters according to the material properties.

\section{2) Kinematics and dynamics analysis:}

According to the requirements of the sucker rod, the input shaft speed of the noncircular gear reversing mechanism is 3rpm, add driver, set the simulation time for 25s, the step is 2500 steps, add the load torque for $10.728 \mathrm{kN} \cdot \mathrm{m}$ on the output gear. After the end of the run, the contact force curves of the noncircular gear pairs are shown in Fig. 2 and Fig.3.

After the reversing of drive wheel and the driven wheel, the output shaft starts the accelerated motion, then the uniform motion and then the decelerated motion, the fluctuation of speed is larger at the moment of the reversing, the maximum is $1218^{\circ}$ s, that is $203 \mathrm{rpm}$. In the accelerated and decelerated operation stage, the velocity curve fluctuates at a relatively uniform motion stage, because the meshing radius and the meshing angle are changing constantly when the noncircular gear meshing, and the time variation of the speed causes the unevenness of the meshing, then causes the velocity fluctuation at relatively large.

And: 


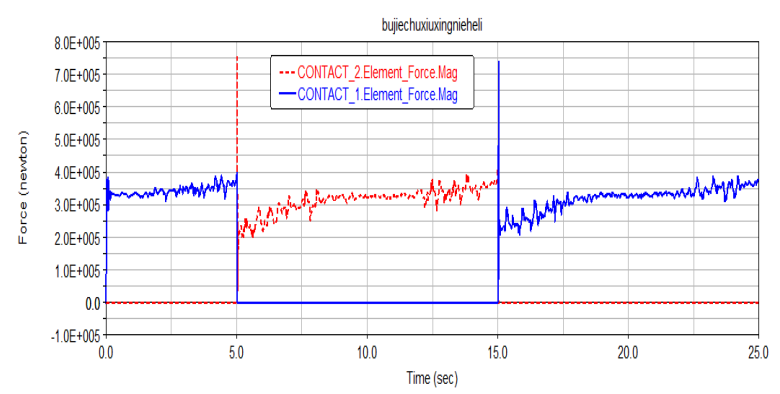

FIGURE II. CONTACT FORCE OF DRIVER GEAR

It can be seen from Figure 2, there is a greater impact for reversing mechanism of incomplete noncircular gear in the moment of reversing, and the maximum impact force is $7.53 \times 10^{5} \mathrm{~N}$, the average force, which close to the reversing of the driver wheel is $3.6 \times 10^{5} \mathrm{~N}$.

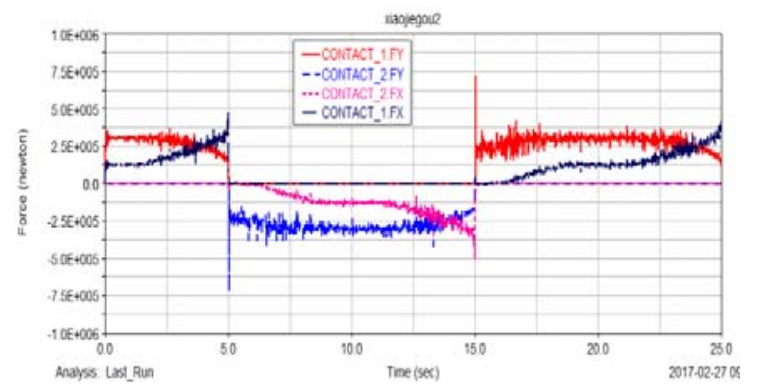

FIGURE III. X-DIRECTION AND Y-DIRECTION COMPONENT OF ACTIVE WHEEL

In the Figure 3, when the output shaft is rotating at constant speed, the fluctuations of the component force of the direction $\mathrm{X}$ and direction $\mathrm{Y}$ about the contact force are smaller. After the change, the component force of the Y-direction has an instant impact. Through the analysis, at $10 \mathrm{~s}$ and $20 \mathrm{~s}$, the $\mathrm{X}$-direction component about driving force represents the driving wheel radial force, and the Y-direction component force represents the tangential force, compare these with the driving wheel radial force and tangential force of the theoretical calculation at $10 \mathrm{~s}$ and $20 \mathrm{~s}$, as shown in Table 1.

TABLE I. COMPARISON BETWEEN THE THEORY AND SIMULATION TANGENTIAL FORCE AND RADIAL FORCE OF ACTIVE WHEEL

\begin{tabular}{llll}
\hline & & \multicolumn{1}{c}{$\begin{array}{c}\text { tangential force } \\
\boldsymbol{F}_{\text {tes }} / \boldsymbol{N}\end{array}$} & \multicolumn{1}{c}{ radial force $\boldsymbol{F}_{\text {res }} / \boldsymbol{N}$} \\
\hline \multirow{2}{*}{$\mathbf{1 0} \mathbf{s}$} & simulation & $3.3408 \times 10^{5}$ & $1.3175 \times 10^{5}$ \\
& theoretical & $3.6197 \times 10^{5}$ & $1.2083 \times 10^{5}$ \\
& error \% & 7.7 & 8.3 \\
& theoretical & $3.4409 \times 10^{5}$ & $1.2524 \times 10^{5}$ \\
\multirow{2}{*}{$\mathbf{2 0 s}$} & simulation & $3.1755 \times 10^{5}$ & $1.1804 \times 10^{5}$ \\
& error\% & 7.7 & 5.7 \\
\hline
\end{tabular}

The transmission efficiency of the bearing and gear is taken into account in the theoretical calculation, and the calculated tangential force and radial force are too large. The error is within reasonable range, and the simulation result is reliable, which can provide reference for the follow-up study.

\section{B. Analysis of Incomplete Noncircular Gear Strength}

The first tooth of the driver wheel is affected by the impact force, although the driver wheel end teeth is not affected by the impact force, when single-tooth meshes, it is possible that the stress of tooth root of the teeth is too large and the teeth are broken, so it is necessary to analyze the flexural strength of the first and the end tooth of the driver wheel.

The worst load position should be found, and the load should be applied when analyzing the bending stress of the noncircular gear tooth root, it is complicated whether the determination of the upper bound or the calculation of the normal force of the tooth profile about this bound. In view of this and the conclusion that change of the noncircular gear normal force along the tooth profile is smaller, the load which is calculated with the node as nominal load when calculate the bending stress of noncircular gear tooth root with equivalent gear, it can be applied to the upper boundary to solve the noncircular gear tooth bending stress after the amendment

1) Stress analysis of driver noncircular gear first teeth:

When the load is applied to the teeth, the stress-strain which far from the root of the root stress strain is almost zero, and only the stress-strain of the forced teeth with its surrounding are obvious. Therefore, in order to improve the efficiency of the calculation, only the driver noncircular gear teeth with its surrounding are taken as the research object, the boundary range of cutting is $1.5 \mathrm{~m}$ from the root of the tooth and the width is $6 \mathrm{~m}$. In this paper, the root of the tooth root is more than $16 \mathrm{~mm}$ and the width is about $65 \mathrm{~mm}$.

When import the cut three-dimensional model of the first tooth of the driver noncircular gear into ANSYS, should avoid the appearance of sharp corners which cause the failure to divide the grid. Select 20CrMnMo as noncircular gear material, the material density is $7800 \mathrm{~kg} / \mathrm{m}^{3}$, elastic modulus is $2.07 \times 10^{11} \mathrm{~Pa}$, Poisson's ratio is 0.25 , the solid element selected SOLID185 when analyze tooth stress-strain.

In this paper, the free grid is adopted to control the length of the whole unit at 0.01 , and the lattice of the finite element model after dividing the mesh is denser

As mentioned earlier, the stress-strain where far from the meshing tooth is almost zero, so we apply fixed constraints on both sides of the subject and the rotation axis to limit all degrees of freedom of the model.

When analyzing the bending stress about tooth root of the first tooth of the noncircular gear, the impact force which the gear switch moment gear should be loaded to prevent the tooth from abruptly breaking due to insufficient bending strength. In order to improve the safety of the teeth, the position of the load is chosen to be close to the tooth side near the top of the tooth. At the top of the tooth, a "narrow surface" with a micro-area width of $0.5 \mathrm{~mm}$ is drawn, and the instantaneous contact force from the simulation is converted into a face force, applied it to the "narrow surface", perpendicular to the face.

After the solution, the stress-strain cloud of the first tooth 
of the driver wheel is obtained. In the most dangerous load conditions which in the moment of conversing, the maximum displacement of the gear is $0.0539 \mathrm{~mm}$, which occurs at the top of the tooth, the maximum bending stress at the root of the tooth is $220 \mathrm{MPa}$, less than the allowable stress of the gear 525.7 MPa.

2) Stress analysis of active noncircular gear end teeth:

In the same way, the part of the tooth root of the end tooth is taken as the object of study, and the stress-strain cloud is obtained as shown in Fig. 4 and Fig.5.

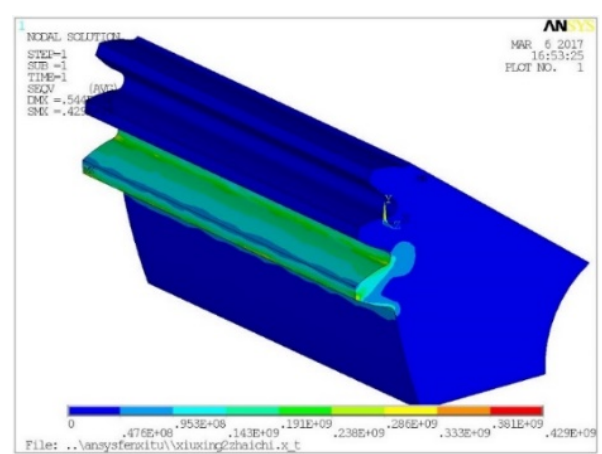

FIGURE IV. TOOTH ROOT STRESS OF DRIVER GEAR LAST TOOTH

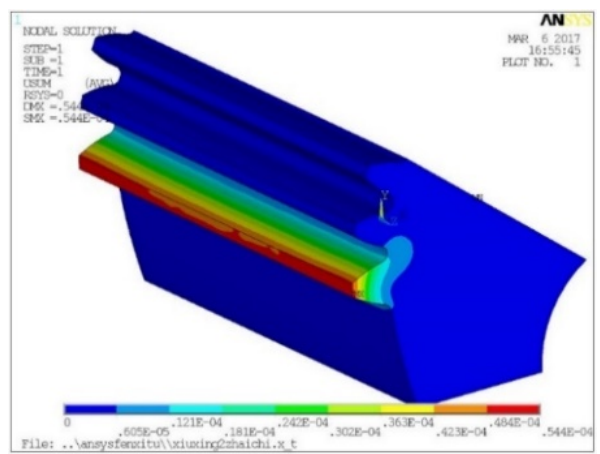

FIGURE V. TOOTH ROOT STRAIN OF DRIVER GEAR FIRST TOOTH

As can be seen from the above figure, the maximum bending stress of the tooth root of the end tooth about the driver wheel is $286 \mathrm{MPa}$ and the maximum displacement is $0.0544 \mathrm{~mm}$, which also occurs at the top of the tooth. Comparing the stress-strain of the first and the end teeth of the driver wheel, it can be found that the stress-strain of the end teeth about driver wheel are larger relatively. The research in future, we could improve the strength of the end tooth through mending tooth shape about the end tooth of driver wheel.

\section{OPTIMIZATION ABOUT GEAR SIZE FOR NONCIRCULAR GEAR REVERSING MECHANISM}

In this paper, the size of the noncircular gear is optimized without changing the relationship about the kinematic angle between drive wheel and driven wheel. Reducing the noncircular gear size, the manufacturing costs and the installation space by changing the noncircular gear modulus and tooth width in the premise of ensuring reliable transmission.

Formula about bending fatigue strength of tooth root:

$$
\sigma_{F}=\frac{2 \times K \times T \times Y_{F a} \times Y_{S a}}{\phi_{d} \times m^{3} \times z^{2}}
$$

Where: $\mathrm{K}$ is the load factor, and it is related to the machine condition, the speed, the gear accuracy, the load sharing distribution and the longitudinal load distribution. But change the gear modulus and tooth width, the load factor unchanged. T is the load torque; $Y_{F a}$ is the tooth profile and $Y_{S a}$ is the stress correction coefficient, they are related to the number of teeth. The optimization of noncircular gear only changes the gear modulus and tooth width, so these two coefficients do not change, and:

$$
\begin{array}{r}
\phi_{d}=\frac{b}{d} \\
d=m \times Z
\end{array}
$$

So:

$$
m^{3} \times \sigma_{F}=\frac{2 \times K \times T_{1} \times Y_{F a} \times Y_{S a}}{\phi_{d} \times Z^{2}}
$$

The original noncircular gear size parameters are shown in Table 2:

TABLE II. ORIGINAL PARAMETERS OF NONCIRCULAR GEAR

\begin{tabular}{llll}
\hline $\boldsymbol{b}$ & $\boldsymbol{m}$ & $\boldsymbol{\sigma}$ & $\boldsymbol{\phi}_{\boldsymbol{d}}$ \\
\hline 340 & 10.518061 & $286 \mathrm{MPa}$ & 1.043
\end{tabular}

Substituting the parameters in the original model:

$$
m^{3} \times \sigma_{F}=332792.162
$$

Optimizing the modulus $\mathrm{m}$ to achieve the purpose of reducing the volume about incomplete noncircular gears, and the optimization problem is as follows:

Objective function:

$$
\min :[\sigma]-\sigma_{F}
$$

Design variable: $\mathrm{m}$

$$
\text { s.t. } \quad m^{3} \times \sigma_{F}=332792.162
$$

This is a single design variable and constrained optimization.

After solving:

$$
m=8.586 \text {. }
$$


According to the formula (6)、 (7) ,calculated:

$$
b=268.84 m m
$$

After rounding the center distance, the parameters of the driver noncircular gear before and after being optimized are shown in Table 3:

TABLE III. GEAR PARAMETERS BEFORE AND AFTER OPTIMIZATION

\begin{tabular}{ccccc}
\hline & $\begin{array}{c}\text { Main, } \\
\text { driven } \\
\text { noncircular } \\
\text { gearcenter } \\
\text { distance } \\
\text { /mm }\end{array}$ & Modulus & $\begin{array}{c}\text { Tooth } \\
\text { width } \\
/ \mathbf{m m}\end{array}$ & $\begin{array}{c}\text { Tooth } \\
\text { width } \\
\text { factor }\end{array}$ \\
\hline $\begin{array}{c}\text { Before } \\
\text { optimization }\end{array}$ & 404 & & \\
After & & 10.518061 & 340 & 1.043 \\
optimization & 320 & & & \\
\hline As & & 8.331137 & 285 & 1.103 \\
\hline
\end{tabular}

As can be seen from Table 3, the modulus of driver noncircular gear after being optimized is reduced by $26 \%$, and the diameter of the noncircular gear is also reduced by $26 \%$ when the number of noncircular gear teeth is constant.

After the model is imported into ADAMS for simulating again, the output shaft speed, acceleration and driving wheel force curve are consistent as the not being optimized, and the maximum impact force in the moment of conversing is also not changed.

\section{CHECKING STRENGTH OF OPTIMIZED MODEL ABOUT NONCIRCULAR GEAR REVERSING MECHANISM}

The strength of the first tooth and the end tooth of the driver wheel is checked, and the stress cloud of the tooth root of the end tooth about driver tooth is shown in Fig.6.

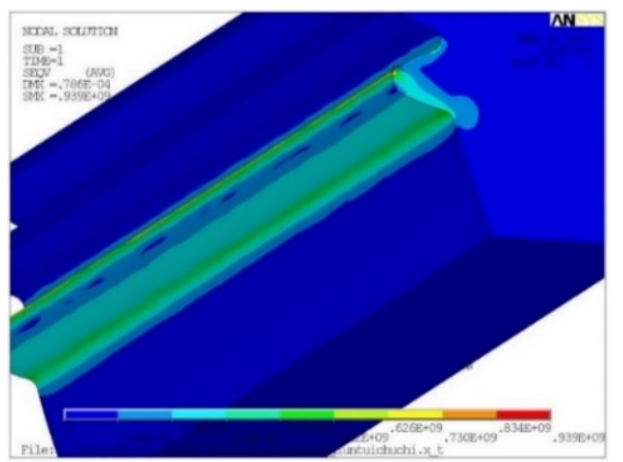

FIGURE VI. TOOTH ROOT STRESS OF DRIVER GEAR LAST TOOTH AFTER OPTIMIZATION

After the optimization, the maximum bending stress of the tooth root of the first tooth about the driving wheel is $247 \mathrm{MPa}$, and its maximum bending stress is $522 \mathrm{MPa}$, and satisfies the bending fatigue strength of the tooth root, which shows that the optimized noncircular gear can meet the strength requirement.

\section{CONCLUSION}

Aimed at the problem about large volume and large margin of the key parts of the new pumping unit which is designed by the traditional empirical formula, we used ADAMS dynamic simulation software to analyze the mechanism of the reversing process, the magnitude of the impact force and the force of dangerous teeth in the moment of reversing. And on this basis, analyzed the bending strength of dangerous Beams by finite element software(Analysis). Then optimized the size of incomplete noncircular gears base on the theoretical bending fatigue strength formula. And the optimized diameter of noncircular gear was reduced by $26 \%$, then Simulated and checked the optimization results. The results showed that the analyzed and optimized methods are correct. This saved material and reduced costs, but also brought greater convenience for noncircular gear processing and production in actual production, which was great significance to the actual production.

\section{ACKNOWLEDGMENT}

We would like to thank Key Research Projects of Higher Education in Henan province(16A460011), who supports the fund project.

\section{REFERENCES}

[1] ZHANG Qiang. Study on system dynamics of rack pumping unit [D]. Southwest Petroleum University, 2014.

[2] YANG Cun. Kinematics and dynamics of noncircular gear [D]. Lanzhou University of Technology, 2014.

[3] CHAI Shifeng, ZHANG Xiling, LI Yulan. Design and kinematics simulation of noncircular gear [J]. Journal of Military Transportation University, 2014 [9]: 36-40.

[4] LIU Yong-ping, YANG Cun, SUN Xuan. Kinematic simulation analysis of noncircular gear based on ADAMS [J]. Journal of Mechanical Transmission, 2014 [6]: 106-109.

[5] XIE Ren-en, ZHOU Kaihong.Modeling simulation of noncircular gear based on ADAMS [J]. Coal Mine Machinery. 2015, 36 (12): 251-253.

[6] T. Hasse. Design of gear drives with congruent noncircular gears [J]. Konstruktion.2000, 0(11/12).

[7] Y. A. Yao,H. S-. Yan. A new method for torque balancing of planar linkages using noncircular gears $[\mathrm{J}]$. Proceedings of the Institution of Mechanical Engineers. Part C, Journal of mechanical engineering science. 2003, 217(c5).

[8] Mechanical design manual (third edition, second volume) [M] .2002.

[9] PU Lianggui, JI Minggang. Mechanical design - 8th Edition [M]. Higher Education Press, 2006.

[10] LI Ji-qiang. Study on meshing characteristics and bearing capacity of noncircular gear transmission [D]. China Academy of Machinery Science and Technology, 2010.

[11] YUAN Wei-hua. Finite element analysis of gear strength based on ANSYS [J]. Journal of Information technology: Academic Research, 2007 (27): 501-503.

[12] LING Youlong. ANSYS 14.0 from entry to master [M]. Tsinghua University Press, 2013. 